\title{
MEASUREMENT AND MODELING OF THREE DIMENSIONAL TARGET STRENGTH OF FISH FOR HORIZONTAL SCANNING SONAR
}

\author{
Muhammad Kurnia \\ Hasanuddin University, Indonesia., kurniamuhammad_unhas@yahoo.co.uk \\ Kohji lida \\ Graduate School of Fisheries Sciences, Hokkaido University, Japan. \\ Tohru Mukai \\ Graduate School of Fisheries Sciences, Hokkaido University, Japan.
}

Graduate School of Fisheries Sciences, Hokkaido University, Japan. Faculty of Marine Sciences and Fisheries,

Follow this and additional works at: https://jmstt.ntou.edu.tw/journal

Part of the Aquaculture and Fisheries Commons

\section{Recommended Citation}

Kurnia, Muhammad; lida, Kohji; and Mukai, Tohru (2011) "MEASUREMENT AND MODELING OF THREE DIMENSIONAL TARGET STRENGTH OF FISH FOR HORIZONTAL SCANNING SONAR," Journal of Marine Science and Technology: Vol. 19: Iss. 3, Article 8.

DOI: $10.51400 / 2709-6998.2194$

Available at: https://jmstt.ntou.edu.tw/journal/vol19/iss3/8

This Research Article is brought to you for free and open access by Journal of Marine Science and Technology. It has been accepted for inclusion in Journal of Marine Science and Technology by an authorized editor of Journal of Marine Science and Technology. 


\section{MEASUREMENT AND MODELING OF THREE DIMENSIONAL TARGET STRENGTH OF FISH FOR HORIZONTAL SCANNING SONAR}

\section{Acknowledgements}

The authors thank Dr. Koki Abe of the National Research Institute of Fisheries Engineering, Japan, for providing the radiographs of samples. We are grateful to Dr. Masahiko Furusawa for providing the modeling and analyzing program of the PSM model. We would also acknowledge Dr. John R. Bower for reading and improving the English of our manuscript. Finally, the authors thank the member of Laboratory of Hydroacoustic Remote Sensing, Hokkaido University for their help in preparation during the experiments. 


\title{
MEASUREMENT AND MODELING OF THREE DIMENSIONAL TARGET STRENGTH OF FISH FOR HORIZONTAL SCANNING SONAR
}

\author{
Muhammad Kurnia****, Kohji Iida*, and Tohru Mukai*
}

Key words: horizontal scanning sonar, three dimensional target strength, prolate spheroid model.

\begin{abstract}
This paper discusses the three-dimensional target strength (3DTS) of fish for a horizontal scanning sonar. Experiments were conducted in a tank using a defrosted Japanese mackerel. Measurements were made by changing the horizontal incident angle of a $50 \mathrm{kHz}$ acoustic beam and the pitch angle of a tethered fish. Following the experiment, morphological characteristics, including the swimbladder size and shape, were measured using soft X-ray and digitized. The theoretical 3DTS was estimated using the prolate spheroid model and compared with the measured 3DTS. Results showed that the TS strongly depended on the fish orientation. The maximum and minimum TS were recorded at the broadside and the head/tail aspect of the fish, respectively. The horizontally averaged TS, which is necessary to estimate fish abundance by horizontal scanning sonar, gradually increased as the pitch angle increased, showing a minimum at $0^{\circ}$ and maximum at $90^{\circ}$. The measured horizontally averaged TS was 3-5 dB lower than the theoretically estimated TS. Possible theoretical, biological, and technical reasons are discussed.
\end{abstract}

\section{INTRODUCTION}

The target strength of fish is an important factor in many applications of fisheries research, especially when converting acoustic backscattering strength to fish abundance. Over the past 70 years, the target strengths have been determined for many commercially important fishes, either by measurements or by theoretical methods [27].

The target strengths of fish are highly variable due to many factors, including morphology, behavior, and acoustic fre-

Paper submitted 07/02/10; revised 08/16/10; accepted 09/01/10. Author for correspondence: Muhammad Kurnia (e-mail: kurniamuhammad_unhas@ yahoo.co.uk).

*Graduate School of Fisheries Sciences, Hokkaido University, Japan.

**Faculty of Marine Sciences and Fisheries, Hasanuddin University, Indonesia. quencies. Even in the same fish, the TS can change due to changes in fish morphological and physiological factors, including body length, tilt angle and morphology of the swimbladder $[2,7,26]$, which is the major reflector and contributes over $90 \%$ of the backscattering from fish [7]. Conversely, the TS of non-swimbladdered species is only about $1 / 10$ of that of swimbladdered species [7].

Generally, the acoustic backscattering cross section is approximately proportionate to the square of fish length $[9,10]$. Also the directivity of the backscattering strength of fish narrows as the fish size increases [9]. This means that the backscattering cross section of fish becomes more sensitive to tilt angle variations as fish size increases.

Echosounder transducers are usually oriented vertically, facing downward to detect fish below it. Therefore the echosounder only deals with a dorsal aspect of the TS of fish. However, horizontal scanning sonars detect fish horizontally, so they require information on the side-aspect TS of fish.

Horizontal scanning sonars are useful for observing fish school behavior and estimating fish school abundances. Many experiments have been conducted to analyze the relationship between TS and fish orientation in shallow water, rivers, lakes, and reservoirs $[4,14,16,19,30]$, and in tank experiments [3, $10,11,18]$. These studies showed that the variation of the yaw $[3,11,22]$ and roll [23], and small $\left(<10^{\circ}\right)$ changes in side aspect angles of fish orientation resulted in large changes (3-8 $\mathrm{dB})$ in TS [5].

On the other hand, some authors have used theoretical models to calculate the TS depending on the orientation of fish $[12,15,28,33]$. To evaluate the 3DTS for sonar surveys, theoretical characteristics of 3DTS with respect to fish orientation have been investigated using a prolate-spheroid mode-series acoustic scattering model [12, 29]

To date, only a few measurements have been conducted to investigate the influence of fish orientation on the 3DTS of fish $[20,29]$ because it is difficult to measure the TS of fish at different aspect angles.

In this study, we propose a method to measure the 3DTS of fish in a tank for all aspect angles, including pitch, yaw and roll angles. Measurement of a Japanese mackerel (Scomber japonicus) were compared with theoretical measurements estimated using a PSM. We show that the horizontally aver 
Table 1. Morphological data of specimen used for target strength measurements.

\begin{tabular}{|c|c|c|c|c|c|c|}
\hline \multirow[b]{2}{*}{ Fish Species } & \multicolumn{3}{|c|}{ Body } & \multicolumn{3}{|c|}{ Swimbladder } \\
\hline & $\begin{array}{c}\text { Length } \\
{[\mathrm{cm}]}\end{array}$ & $\begin{array}{l}\text { Height } \\
{[\mathrm{cm}]}\end{array}$ & $\begin{array}{c}\text { Weight } \\
{[\mathrm{g}]}\end{array}$ & $\begin{array}{c}\text { Length } \\
{[\mathrm{cm}]}\end{array}$ & $\begin{array}{c}\text { Height } \\
{[\mathrm{cm}]}\end{array}$ & $\begin{array}{c}\text { Inclination angle } \\
{[\mathrm{deg}]}\end{array}$ \\
\hline $\begin{array}{l}\text { Japanese mackerel } \\
\text { Scomber japonicus }\end{array}$ & 21.4 & 4.1 & 107.8 & 5.3 & 1.44 & 8.5 \\
\hline
\end{tabular}

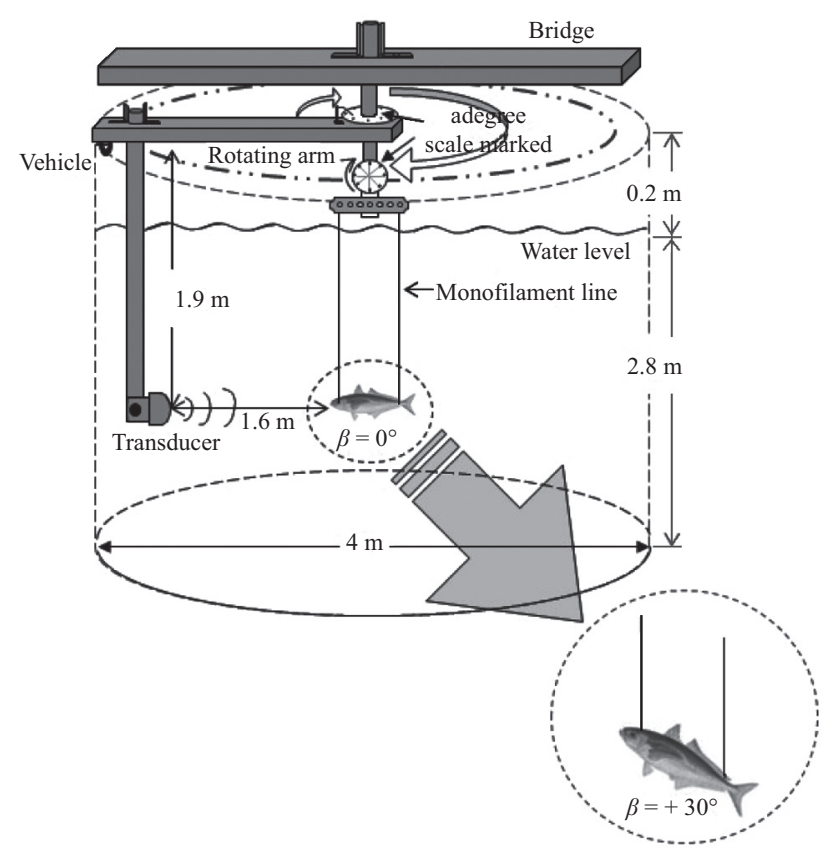

Fig. 1. The configuration of the experimental setup to measure the 3DTS of fish in water tank. The orientation of fish at the pitch angles of $0^{\circ}$ and $30^{\circ}$ are shown in the figure.

aged TS is an important factor for estimating the abundance of fish schools using horizontal scanning sonars. Characteristics of the horizontally averaged TS are compared to measured and theoretically estimated TS values.

\section{MATERIALS AND METHODS}

\section{Measurement of Three Dimensional Target Strength of Fish in a Tank}

Experiments were conducted in a cylindrical water tank measuring $3 \mathrm{~m}$ in depth and $4 \mathrm{~m}$ in diameter filled with freshwater (Fig. 1). TS data were collected with a commercial echosounder (CVS-888, KODEN) connected to a $50 \mathrm{kHz}$ transducer with a $3 \mathrm{~dB}$ beam width of $11.2^{\circ}$ and $1 \mathrm{~ms}$ pulse length. A transducer was mounted on the edge of the rotating arm and suspended at mid-water depth in the tank facing horizontally toward the fish (Fig. 1). Prior to the measurements, the echosounder system was calibrated using a tungsten carbide sphere of $38.1 \mathrm{~mm}$ diameter.

The fish used was a defrosted Japanese mackerel, Scomber japonicus, $214 \mathrm{~mm}$ in total length and $107.8 \mathrm{~g}$ in body weight.
The fish was caught by jigging and frozen after capture to keep the original swimbladder shape until the start of the experiment. The fish was thawed in ice water over a 12-hour period, before the X-ray measurements were performed.

Before the experiment, a soft X-ray imaging system (PROTEST100, Softex) was used to obtain morphological data of the fish including its internal organs $[1,25,26,32]$. Outlines of the lateral and dorsal shape of the swimbladder and the body were digitized following the soft X-ray images at $1-\mathrm{cm}$ intervals using the image processing software Didger (Golden software). The digitized data used to calculate the theoretical TS by the PSM program are shown in Table 1 .

The fish was carefully suspended using a pair of nylon monofilament lines of $0.205 \mathrm{~mm}$ diameter with two small hooks. The hooks were attached to the head and the caudal part on the dorsal side of fish to change the pitch angle (Fig. 1). The fish was lowered to the center of the water tank at a depth of $190 \mathrm{~cm}$ and positioned $160 \mathrm{~cm}$ from the transducer.

The procedure for measuring the 3DTS was as follows. At first, keeping the pitch angle of the fish at $0^{\circ}$, the transducer was slowly rotated in the horizontal plane around the fish from $-90^{\circ}$ (tail aspect) to $+90^{\circ}$ (head aspect) centered to the lateral aspect of the fish. The echo amplitude from the fish was measured at one degree intervals. Next, the pitch angle of the fish was increased to $10^{\circ}$ and the transducer was rotated horizontally in the same way described above. This procedure was repeated at $10^{\circ}$ pitch angle intervals between $-90^{\circ}$ and $+90^{\circ}$. The measurements were performed only for the horizontal incident angle between $-90^{\circ}$ and $+90^{\circ}$ because the TS function of opposite side is thought to be symmetrical.

The orientation of the fish was kept stable. The pitch angle of the fish was determined by reading an inclination angle of the hanger that suspended the fish.

\section{Estimation of Three-Dimensional Target Strength of Fish}

The maximum TS was defined as the peak value in the TS function against the horizontal incident angle of the fish. The averaged TS was determined by averaging the TS function with respect to the fish orientation [6].

Scatterer orientation can be described by the orientation angles $\left(\theta_{t}, \phi_{t}\right)$ which specify the scatterer orientation observed from a collocated transmitter and receiver transducer. In this case, the direction of the incident and scatterer sound pulse was the same direction in the coordinates. The direction of the incident sound is described by the unit $\hat{u}_{t}$. Thus, the fish ori- 


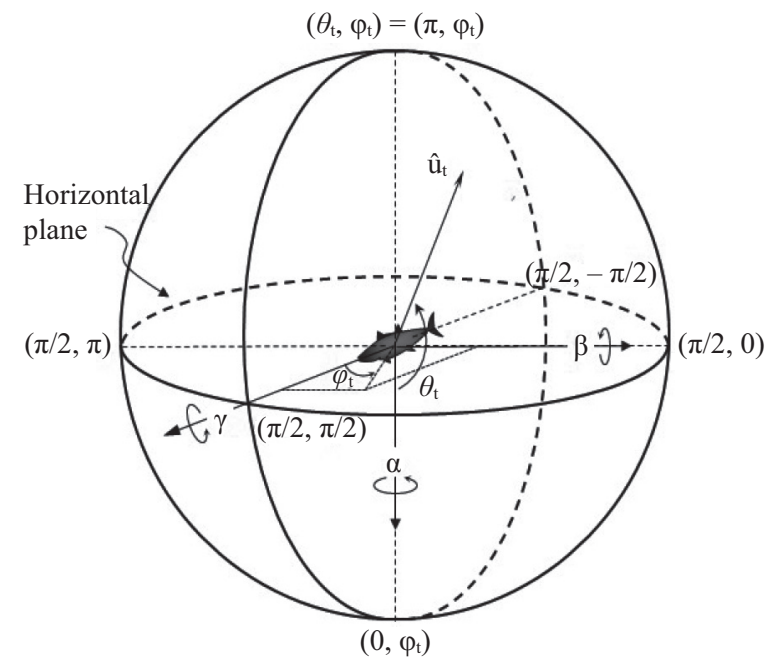

Fig. 2. The description of fish orientation by spherical coordinates. $\theta_{t}$ and $\varphi_{\mathrm{t}}$ are the orientation angles viewed from the sonar transducer and the unit $\hat{u}_{t}$ indicates the direction of the incident sound.

entation is defined by the yaw $(\alpha)$, pitch $(\beta)$, and roll $(\gamma)$ angle of the fish. The interpretation of scatterer orientation of a fish is illustrated in Fig. 2.

According to Tang et al. [29], the averaged backscattering cross-section depends on the distribution of fish orientation, which can be described by an integral over the joint distributions of $\alpha, \beta$, and $\gamma$. Assuming that these distributions are independent of each other, then

$$
\begin{aligned}
<\sigma_{\mathrm{bs}}>= & \int_{-\pi / 2}^{\pi / 2} \int_{-\pi / 2}^{\pi / 2} \int_{-\pi}^{\pi} \sigma_{\mathrm{bs}}\left(\theta_{\mathrm{t}}, \phi_{\mathrm{t}}\right) \\
& \times \quad f(\alpha) f(\beta) f(\gamma) d \alpha d \beta d \gamma
\end{aligned}
$$

where $\theta_{\mathrm{t}}$ and $\phi_{\mathrm{t}}$ are the orientation angles viewed from the sonar transducer (Fig. 2) and $f(\alpha), f(\beta)$, and $f(\gamma)$ are the probability density functions (PDFs) of a fish in yaw, pitch, and roll angles, respectively.

The distribution of fish orientation can be influenced by some factors, therefore it is necessary to make some assumptions regarding the averages and standard deviations of the orientation distributions. When using a horizontal scanning sonar, the tilt angle of the acoustic beam is nearly $0^{\circ}$ and assumed hereafter to be $0^{\circ}$. Also the roll angle of fish is assumed to be $0^{\circ}$. Then, the averaged backscattering cross-section of fish at the pitch angle $\beta$ may be expressed by:

$$
<\sigma_{\mathrm{bs}}(\beta)>=\int_{-\pi}^{\pi} \sigma_{\mathrm{bs}}\left(\theta_{\mathrm{t}}, \phi_{\mathrm{t}}\right) f(\alpha) d \alpha
$$

Furthermore, assuming the horizontal orientation distribution of fish is random, namely $f(\alpha)=1 / 2 \pi$ and then, the orientation angles viewed from the sonar transducer are assumed to be the pitch and yaw angles of fish in the fish school, namely $\left(\theta_{\mathrm{t}}, \phi_{\mathrm{t}}\right)=(\beta, \alpha)$. Therefore, Eq. (2) can be further simplified as:

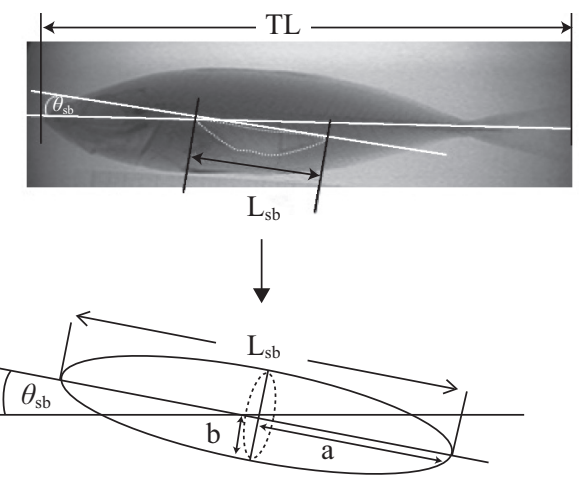

Fig. 3. Geometry of fish body, swimbladder, and prolate spheroid model. $\mathrm{TL}, \mathrm{L}_{\mathrm{sb}}, \theta_{\mathrm{sb}}, \boldsymbol{a}$, and $\boldsymbol{b}$ denote fish body length, swimbladder length, inclination angle of swimbladder, the major and minor axes of prolate spheroid model, respectively.

$$
<\sigma_{\mathrm{bs}}(\beta)>=\frac{1}{2 \pi} \int_{-\pi}^{\pi} \sigma_{\mathrm{bs}}(\beta, \alpha) d \alpha
$$

Then, the horizontally averaged $T S$ for the specific pitch angle $\beta$ of a fish can be calculated by

$$
<T S(\beta)>=10 \log _{10}<\sigma_{\mathrm{bs}}(\beta)>
$$

Meanwhile, the theoretical horizontally averaged TS is given by averaging the backscattering amplitude by the theoretical model. The PSM model is one of the theoretical methods used to calculate the backscattering cross-section of fish as a function of fish morphology (i.e., swimbladder morphology, size and shape) and orientation. The PSM approximates the swimbladder as a prolate-spheroid. The major axes and minor axes of the prolate-spheroid were determined by measuring outlines of the swimbladder. The geometries of the fish body, swimbladder, and the prolate-spheroid modeling swimbladder are shown in Fig. 3.

The scattering amplitude functions in the far field approximation are described by the form function $f_{\infty}$ :

$$
\begin{aligned}
f_{\infty}\left(\theta, \phi \mid \theta^{\prime}, \phi^{\prime}\right)= & \frac{2}{j k_{0}} \sum_{m=0}^{\infty} \sum_{n=m}^{\infty} \frac{\varepsilon_{m}}{N_{m n}\left(h_{0}\right)} S_{m n}\left(h_{0}, \cos \theta^{\prime}\right) \\
& \times A_{m n} S_{m n}\left(h_{0}, \cos \theta\right) \cos m\left(\phi-\phi^{\prime}\right)
\end{aligned}
$$

where $\theta, \theta^{\prime}$ and $\phi, \phi^{\prime}$ are the scattering and incident angles, respectively, $\varepsilon_{\mathrm{m}}$ is the Neumann factor, $h_{0}=k_{0} q\left(k_{0}\right.$ is the wave number in the surrounding water and $q$ is the semi-focal length), $S_{m n}$ is the prolate-spheroid angular function of the first kind of order $m$ and degree $n, N_{m n}$ is the norm of $S_{m n}$, and $A_{m n}$ is the expansion coefficient of the scattering function determined by the boundary conditions [12].

The target strength TS is related to $f_{\infty}$ as:

$$
T S(\theta)=20 \log _{10} F=20 \log _{10}\left|f_{\infty}(\theta, 0 \mid \pi-\theta, \pi)\right|
$$


Table 2. Parameters used for theoretical estimation of target strength by the Prolate Spheroid Model (PSM).

\begin{tabular}{|c|c|c|c|c|c|c|c|c|}
\hline \multirow[b]{2}{*}{ Model } & \multicolumn{3}{|c|}{ Orientation distribution } & \multicolumn{2}{|c|}{ Acoustic beam } & \multicolumn{3}{|c|}{ Geometry of swimbladder } \\
\hline & Yaw & Pitch & Roll & $\begin{array}{c}\text { Frequency } \\
{[\mathrm{kHz}]}\end{array}$ & $\begin{array}{c}\text { Tilt angle } \\
{\left[^{\circ}\right]} \\
\end{array}$ & $\begin{array}{c}\text { Major radius a } \\
{[\mathrm{cm}]}\end{array}$ & $\begin{array}{c}\text { Minor radius b } \\
{[\mathrm{cm}]}\end{array}$ & $\begin{array}{c}\text { Aspect ratio } \\
\mathrm{b} / \mathrm{a}\end{array}$ \\
\hline PSM & $\begin{array}{c}\text { Uniform } \\
\left(-180^{\circ} \sim 180^{\circ}\right)\end{array}$ & $\begin{array}{c}\text { Constant } \\
0^{\circ}, 10^{\circ}, \ldots 90^{\circ}\end{array}$ & $\begin{array}{c}\text { Constant } \\
\left(0^{\circ}\right)\end{array}$ & 50 & 0 & 2.65 & 0.72 & 0.27 \\
\hline
\end{tabular}

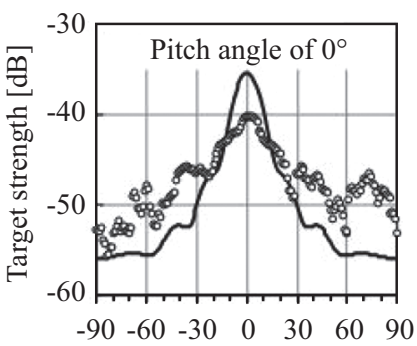

Horizontal incident angle $\left[^{\circ}\right]$

(a)

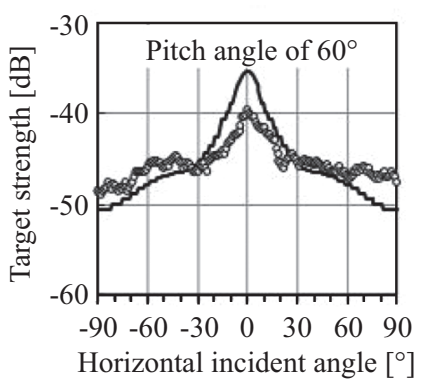

(c)

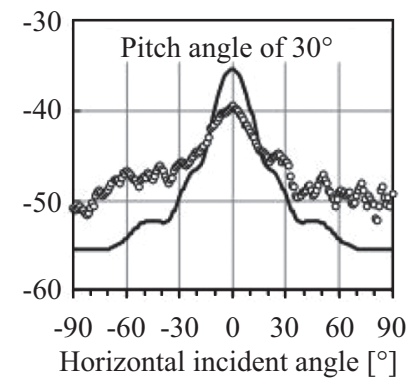

(b)

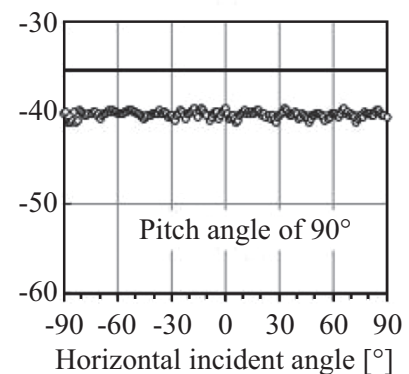

(d)

Fig. 4. Comparison between the theoretical horizontal TS functions and measured horizontal TS functions at the pitch angle of (a) $0^{\circ}$, (b) $30^{\circ}$, (c) $60^{\circ}$ and (d) $90^{\circ}$. The open circles indicate the measured values and the solid lines indicate the estimated theoretical values, respectively.

where $F$ is defined as the absolute value of the far field backscattering amplitude. Then the theoretical averaged TS is also calculated by Eq. (4).

The swimbladder was modeled as a vacant prolate-spheroid. He geometries of swimbladder were determined based on the outlines of its dorsal and lateral aspects, which were obtained by tracing X-ray images. Parameters used for the theoretical estimation of target strength are shown in Table 2. The geometry of swimbladder, $2 a$ as the major and $2 b$ as the minor axis are given by the length and maximum diameter of swimbladder, respectively.

\section{RESULTS AND DISCUSSION}

\section{Characteristics of Three Dimensional Target Strength of Fish}

Fig. 4 shows the measured horizontal TS functions at pitch angles of (a) $0^{\circ}$, (b) $30^{\circ}$, (c) $60^{\circ}$, and (d) $90^{\circ}$. In all horizontal TS functions, the maximum TS was found at a horizontal

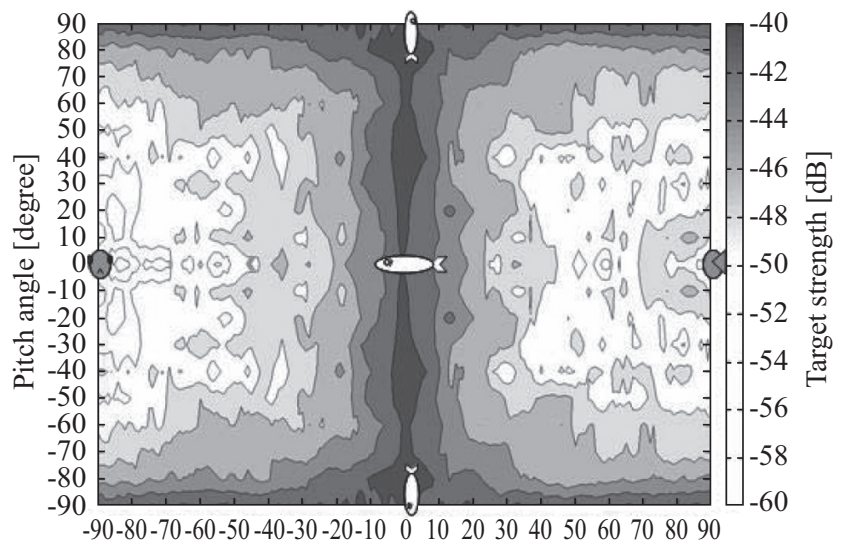

Fig. 5. Visualization of three-dimensional TS pattern of fish by contour map to explain the relationship between TS and fish orientation. The horizontal axis denotes the horizontal incident angle, the vertical axis denotes the pitch angle of fish, and the darkness in the contour map represents the TS value.

incident angle of $0^{\circ}$, and the TS decreased as the horizontal incident angle increased. The decreasing pattern of the horizontal TS changed more slightly as pitch angle increased. The maximum TS was about the same $(-39 \mathrm{~dB})$ at all pitch angles. This is reasonable because this direction is the side aspect for all the pitch angles. Lastly the TS function at a $90^{\circ}$ pitch angle (this is actually roll aspect) showed an omni- directional pattern with the maximum TS (Fig. 4(d)). This shows that the TS pattern of fish depends highly on the orientation of the fish $[11,12,16]$.

Fig. 4 also shows a comparison between the theoretical horizontal TS functions and the measured horizontal TS functions at pitch angles (a) $0^{\circ}$, (b) $30^{\circ}$, (c) $60^{\circ}$, and (d) $90^{\circ}$. The results show that the theoretical estimation and the measurements were not in close agreement. However, the theoretical estimation explained that the maximum TS was found at a horizontal incident angle of $0^{\circ}$, and the TS decreased slightly with an increase of the horizontal incident angles in agreement with the measurements. Meanwhile, at a pitch angle of $90^{\circ}$, the TS was the same at all horizontal incident angles for both theoretical and measured values (Fig. 4(d)).

Fig. 5 shows the three-dimensional TS pattern of fish by contour map to describe the relationship between the TS and the orientation of fish. Assuming the symmetry of the TS pattern, the pattern in the horizontal incident angle from $0^{\circ}$ to $90^{\circ}$ and the pitch angle from $0^{\circ}$ to $90^{\circ}$ was duplicated to other angle ranges. The TS changed drastically with changing hori- 


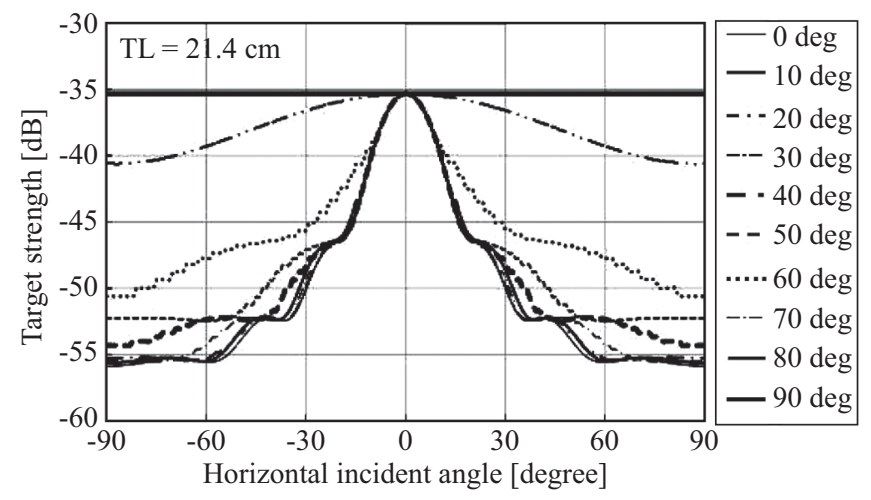

Fig. 6. The theoretical TS functions by PSM model against the horizontal incident angle of fish estimated by changing the pitch angle of fish from $0^{\circ}$ to $90^{\circ}$.

zontal incident angle at small pitch angles, because these angles correspond to yaw patterns of the fish TS. However the TS changed more smoothly with changing horizontal incident angle at large pitch angles where nearly the roll pattern of fish TS was observed. This indicates that the variation of TS was strongly associated with fish orientation. Namely the TS in lateral aspect $\left(0^{\circ}\right)$ showed the maximum value, whilst the TS in head $\left(+90^{\circ}\right)$ or tail aspect $\left(-90^{\circ}\right)$ showed the minimum value. These results agree with several studies that reported that fish orientation has a significant influence on variation of fish TS $[3,13,17,21,29]$. To explain the characteristics of 3DTS of fish, the PSM was incorporated to estimate the TS theoretically [12].

\section{Estimation of Horizontally Averaged Target Strength of Fish}

To investigate how a change of pitch angle of fish affects the horizontally averaged TS, the theoretical TS functions against the horizontal incident angle of fish were estimated by changing the pitch angle of fish from $0^{\circ}$ to $90^{\circ}$ using the PSM shown in Fig. 6 . In the figure, the maximum TS was found at a horizontal incident angle of $0^{\circ}$ when the fish was oriented perpendicularly to the acoustic beam, and the TS decreased slightly by increasing horizontal incident angle of the fish. The maximum TS did not change depending on the pitch angle of the fish. Similar observations on the general characteristics of horizontal TS of fish have been reported in past studies [3, 11, 29].

Fig. 7 shows the relation between the horizontally averaged TS and pitch angle of fish. In the tank measurements, the horizontally averaged TS $(-46.0 \mathrm{~dB})$ was lowest at a pitch angle of $0^{\circ}$ and highest TS $(-40.2 \mathrm{~dB})$ at a pitch angle of $90^{\circ}$, with a difference of $5.8 \mathrm{~dB}$. In the theoretical estimation, the minimum horizontally averaged TS $(-43.3 \mathrm{~dB})$ also occurred at a pitch angle of $0^{\circ}$, and the maximum $(-34.9 \mathrm{~dB})$ also occurred at a pitch angle of $90^{\circ}$, with a difference of $8.4 \mathrm{~dB}$.

Generally, at pitch angles $<60^{\circ}$, the horizontally averaged TS of fish gradually increased with an increase of the pitch

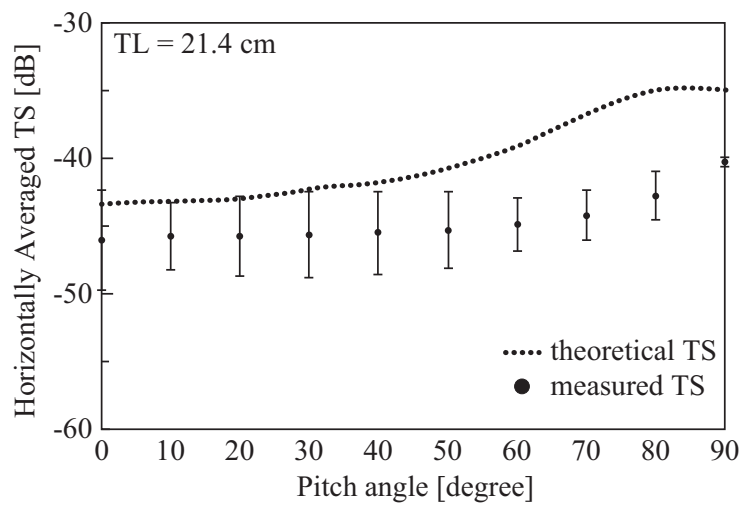

Fig. 7. The horizontally averaged TS of Japanese mackerel, Scomber japonicus by measurement (filled circles with range bars) and by PSM model estimated theoretically (dotted line).

angle, while at pitch angles $>60^{\circ}$, the horizontally averaged TS rapidly increased with an increase of pitch angle of the fish.

Effects of pitch angle change at small pitch angles on the horizontally averaged TS were insignificant, and errors were $1 \mathrm{~dB}$ at pitch angles of $0^{\circ}$ to $55^{\circ}$ in measurement value and $0^{\circ}$ to $30^{\circ}$ in theoretical values. This result means that the error due to the change of horizontally averaged TS caused by the change of pitch angle of fish in small pitch angles was insignificant in estimating fish abundance using horizontal scanning sonar.

\section{Consideration on the Discrepancy between Experiment and Theoretical Model}

As for the discrepancy of the TS between measurement and theoretical estimation, we discussed about the possible reasons from the viewpoint of theoretical, biological, and technical problems in the measurements.

Generally, measurement of the TS of fish in a water tank has to be conducted under so called "far field" conditions. If the distance between the transducer and the fish target is small, the echo amplitude and the directivities may not be measured accurately due to near field effects. The range of "near field" is explained by the Rayleigh distance, $\mathrm{RD}$, which is defined for the sound source as $\mathrm{RD}=\pi \mathrm{a}^{2} / \lambda$, and for the fish target as $\mathrm{RD}=\pi \mathrm{L}^{2} / \lambda$. Here, $\lambda$ is a wavelength, $a$ is a radius of the transducer, and L is a fish body length [31].

In this study, the distance between the transducer and the fish $(r)$ was $1.6 \mathrm{~m}$. Assuming the radius of the transducer, $a=$ $30 \mathrm{~mm}$, the acoustic wavelength, $\lambda=30 \mathrm{~mm}$, the fish body length, $\mathrm{L}=214 \mathrm{~mm}$, and the swimbladder length, $\mathrm{SBL}=55.5$ $\mathrm{mm}$, the estimated Rayleigh distance of the sound source was $0.094 \mathrm{~m}$, which is smaller than $r=1.6 \mathrm{~m}$. Meanwhile the Rayleigh distance from the reflector should be considered from the fish body and the swimbladder, respectively. The estimated Rayleigh distance from the swimbladder $\left(\mathrm{RD}_{\mathrm{sbl}}\right)$ was $0.32 \mathrm{~m}$, which is smaller than $1.6 \mathrm{~m}$. However the Rayleigh distance from the fish body, $\left(\mathrm{RD}_{\mathrm{bd}}\right)$ was $4.8 \mathrm{~m}$ which is larger than the distance measurement range, $r=1.6 \mathrm{~m}$. 
This means the echo amplitude and the directivity by the fish body cannot be measured properly. However the echo by the fish body is small enough compared to the echo from the swimbladder [7, 8], so the near field effects of fish body to the TS of fish were thought to be insignificant.

Next we consider the influence of biological change of the fish on the TS. The sample was caught by jigging and was immediately frozen in a freezer. After three days, it was thawed to take X-ray pictures and frozen again in a freezer. After two days, it was thawed to measure the TS. Moreover it took more than 20 hours to measure the TS in the freshwater tank. During the repeated freezing and thawing, the swimbladder in the fish body might have changed in shape due to the release of gases. If the swimbladder is deflated to half its volume, the TS of fish could decrease more than $3 \mathrm{~dB}$. The beam pattern of fish TS could also possibly become more flat.

Lastly we discuss from the technical view point of measurement. In a acoustic experiment in a water tank, echoes will occur from the water surface and tank walls. In this experiment, as there were many echoes that interfered with the fish echoes, and it was difficult to measure very small echoes from the fish. For further precise and sensitive measurements, a large tank and a side-lobe depressed transducer should be used.

\section{CONCLUSION}

The three-dimensional target strength (3DTS) of Japanese mackerel at $50 \mathrm{kHz}$ was measured in a water tank and compared with theoretically estimated TS.

The directivity of the 3DTS of fish was strongly associated with fish orientation. The target strength changed drastically with changing pitch angle and yaw angle of fish, but remained fairly constant as the roll angle of the fish changed. The maximum TS was found at the broadside aspect, and the minimum TS was found at the head/tail aspect of the fish.

The horizontally averaged TS of fish, which is necessary to estimate fish abundance by horizontal sonar, gradually increased with an increase of the pitch angle at small pitch angles. Ranges of pitch angle affect to the horizontally averaged TS with errors $1 \mathrm{~dB}$ ranged from $0^{\circ}$ to $55^{\circ}$ in measurement value and from $0^{\circ}$ to $30^{\circ}$ in theoretical values. Accordingly, in the natural condition of fish, the effect of pitch angle changes on the horizontally averaged TS was thought to be insignificant.

\section{ACKNOWLEDGMENTS}

The authors thank Dr. Koki Abe of the National Research Institute of Fisheries Engineering, Japan, for providing the radiographs of samples. We are grateful to Dr. Masahiko Furusawa for providing the modeling and analyzing program of the PSM model. We would also acknowledge Dr. John R. Bower for reading and improving the English of our manuscript. Finally, the authors thank the member of Laboratory of
Hydroacoustic Remote Sensing, Hokkaido University for their help in preparation during the experiments.

\section{REFERENCES}

1. Abe, K., Sadayasu, K., Sawada, K., Ishii, K., and Takao, Y., "Precise target strength measurement and morphological observation of juvenile walleye pollock (Theragra chalcogramma)," Oceans 2004-MTS/IEEE Kobe Techno-Ocean, Vol. 1, pp. 370-374 (2004).

2. Blaxter, J. H. S. and Batty, R. S., "Swimbladder behaviour and target strength," Rapports et Procès-Verbaux des Rèunions du Conseil Permanent Internationale pour l'Exploration de la Mer, Vol. 189, pp. 233-244 (1990).

3. Boswell, K. M. and Wilson, C. A., "Side-aspect target strength measurements of bay anchovy (Anchoa mitchilli) and Gulf menhaden (Brevootia patronus) derived from ex situ experiments," ICES Journal of Marine Science, Vol. 65, pp. 1012-1020 (2008).

4. Burwen, D. L., Nelson, P. A., Fleischman, S. J., Mulligan, T. J., and Horne, J. K., "The complexity of narrowband echo envelopes as a function of fish side-aspect angle," ICES Journal of Marine Science, Vol. 64, pp. 1066-1074 (2007).

5. Dahl, P. H. and Mathiasen, O. A., "Measurement of fish target strength and associated directivity at high frequencies," Journal of Acoustical Society of America, Vol. 73, No. 4, pp. 1205-1211 (1983).

6. Foote, K. G., "Averaging of fish target strength functions," Journal of Acoustical Society of America, Vol. 67, pp. 504-515 (1980).

7. Foote, K. G., "Important of the swimbladder in acoustic scattering by fish: a comparison of gadoid and mackerel target strengths," Journal of Acoustical Society of America, Vol. 67, pp. $2084-2089$ (1980).

8. Foote, K. G., "Rather high frequency sound scattering by swimbladdered fish," Journal of Acoustical Society of America, Vol. 78, pp. 688-700 (1985).

9. Foote, K. G. and Nakken, O., "Dorsal aspect target strength functions of six fishes at two ultrasonic frequencies," Fisken og Havet Rapport og Meldinger Fra Fiskeridirektoratets havforskningsinstitutt Scernummer Bergen, Vol. 3, p. 95 (1978).

10. Frouzova, J. and Kubecka, J., "Change of acoustic target strength during juvenile perch development," Fisheries Research, Vol. 66, pp. 355-361 (2004).

11. Frouzova, J., Kubecka, J., Helge Balk, and Jan Frouz, "Target strength of some European fish species and its dependence on fish body parameters," Fisheries Research, Vol. 75, pp. 86-96 (2005).

12. Furusawa, M., "Prolate spheroidal models for predicting general trends of fish target strength," Journal of Acoustical Society of Japan (E), Vol. 9, pp. 13-24 (1988).

13. Henderson, M. J., Horne, J. K., and Towler, R. H., "The influence of beam position and swimming direction on fish target strength," ICES Journal of Marine Science, Vol. 65, pp. 226-237 (2007).

14. Horne, J. K. and Clay, C. S., "Sonar systems and aquatic organisms: matching equipment and model parameters" Canadian Journal of Fisheries and Aquatic Sciences, Vol. 55, pp. 1296-1306 (1998).

15. Kang, D. H., Sadayasu, K., Mukai, T., Iida, K., Hwang, D. J., Sawada, K., and Miyashita, K., "Target strength estimation of black porgy Acanthopagrus schlegeli using acoustic measurements and scattering model," Fisheries Science, Vol. 70, pp. 819-828 (2004).

16. Knudsen, F. R. and Saegrov, H., "Benefits from horizontal beaming during acoustic survey: application to three Norwegian lakes," Fisheries Research, Vol. 56, pp. 205-211 (2002).

17. Kubecka, J., "Simple model on the relationship between fish acoustical target strength and aspect for high-frequency sonar in shallow water," Journal of Applied Ichthyology, Vol. 10, pp. 75-81 (1994).

18. Kubecka, J. and Duncan, A., "Acoustic size vs real size relationship for common species of riverine fish," Fisheries Research, Vol. 35, pp. 115 125 (1998)

19. Kubecka, J. and Wittingerova, M., "Horizontal beaming as a crucial 
component of acoustic fish stock assessment in freshwater lakes," Fisheries Research, Vol. 35, pp. 99-106 (1998).

20. Kurnia, M., Mukai, T., and Iida, K., "Omnidirectional target strength of Horse mackerel (Trachurus japonicus) for sonar survey," 2008 Proceedings of Meeting of The Marine Acoustics Society of Japan, pp. 45-46 (2008)

21. Lilja, J., Marjomaki, T. J., Jurvelius, J., Rossi, T., and Heikkola, E., "Simulation and experimental measurement of side-aspect target strength of Atlantic salmon (Salmo salar) at high frequency," Canadian Journal Fisheries and Aquatic Sciences, Vol. 61, pp. 2227-2236 (2004).

22. Love, R. H., "Target strength of an individual fish at any aspect," Journal of Acoustical Society of America, Vol. 62, pp. 1397-1403 (1977).

23. Nakken, O. and Olsen, K., "Target strength measurements of fish," Rapports et Procès-Verbaux des Rèunions du Conseil Permanent Internationale pour l'Exploration de la Mer, Vol. 170, pp. 52-69 (1977).

24. Rose, G. A. and Porter, D. R., "Target strength studies on Atlantic cod (Gadus morua) in Newfoundland waters," ICES Journal of Marine Science, Vol. 53, pp. 259-269 (1996).

25. Sawada, K., Miyanohana, Y., and Ishii, K., "Precise target strength pattern measurement in an indoor tank," Journal of Acoustical Society of Japan (E), Vol. 18, No. 5, pp. 231-238 (1997).

26. Sawada, K., Ye, Z., Kieser, R., McFarlane, G. A., Miyanohana, Y., and Furusawa, M., "Target strength measurements and modeling of walleye pollock and pacific hake," Fisheries Science, Vol. 65, No. 2, pp. 193-205 (1999).

27. Simmonds, E. J. and MacLennan, D. N., Fisheries Acoustic. Theory and Practice. 2nd Edition, Blackwell Science, Oxford, UK, p. 437 (2005).

28. Stanton, T. K., "Sound scattering by cylinders of finite length. I. Fluid cylinders," Journal of Acoustical Society of America, Vol. 83, pp. 55-63 (1988).

29. Tang, Y., Nishimori, Y., and Furusawa, M., "The average three-dimensional target strength of fish by spheroid model for sonar surveys," ICES Journal of Marine Science, Vol. 66, pp. 1176-1183 (2009).

30. Trevorrow, M. V., "Detection of migrating fish in the Fraser River using 100-kHz side can sonars," Canadian Journal of Fisheries and Aquatic Sciences, Vol. 54, pp. 1619-1629 (1997).

31. Tucker, D. G., "Nearfield effects in electronic scanning sonar," Journal of Sound and Vibration, Vol. 8, No. 3, pp. 355-363 (1968).

32. Yasuma, H., Sawada, K., Oshima, T., Miyashita, K., and Aoki, I., "Target strength of meso pelagic lantern fishes (family Myctophidae) based on swimbladder morphology," ICES Journal of Marine Science, Vol. 60, pp. 584-591 (2003)

33. Ye, Z. and Furusawa, M., "Modeling of target strength of swimbladder fish at high frequency," Journal of Acoustical Society of Japan (E), Vol. 16, No. 6, pp. 371-379 (1995). 